\title{
Report on Seismic Damage of Lifts and Escalators by Large Earthquakes in Japan
}

\author{
Satoshi Fujita ${ }^{1}$, Motoo Shimoaki ${ }^{2}$ and Keisuke Minagawa ${ }^{3}$ \\ 1 Tokyo Denki University, Department of Mechanical Engineering, \\ 5 Senju-Asahi-cho, Adachi-ku, Tokyo 120-8551, Japan, sfujita@cck.dendai.ac.jp \\ 2 Tokyo Denki University, Department of Mechanical Engineering, \\ 5 Senju-Asahi-cho, Adachi-ku, Tokyo 120-8551, Japan, 15905@ms.dendai.ac.jp \\ ${ }^{3}$ Saitama Institute of Technology, Department of Mechanical Engineering, \\ 1690 Fusaiji, Fukaya, Saitama 369-0293, Japan, mina@sit.ac.jp
}

Keywords: Earthquake Damage, The Great East Earthquake, Seismic Design Guideline.

\begin{abstract}
The devastating earthquake of Mw9.0, so-called the Great East Japan Earthquake, hit the Tohoku district, north east part of Japan on March 11, 2011. About 16,000 people died and 2,500 people were missing by the strong motion and tsunami, and the economic damage was estimated about 16.9 trillion yen in addition to the influence by the nuclear accident of Fukushima Daiichi Nuclear Power Plant. In addition to the main shock, many strong aftershocks occurred in the long term. After that, strong near-field earthquakes called the Kumamoto Earthquake and the North Osaka Earthquake occurred in 2016 and 2018. Many lifts and escalators were damaged in these earthquakes as well as building structures and industrial facilities. Therefore, this paper reports seismic damage of lifts and escalators by large earthquakes in Japan. At first, changes of the Seismic Design Guideline in Japan are introduced. Then a summary of the damage regarding the lifts and escalators was provided in order to confirm effectiveness of Seismic Design Guideline and to contribute improvement of the seismic design for forthcoming destructive earthquakes. The damage is analysed from the viewpoint of causes and the edition of Seismic Design Guidelines. Although the many of the buildings were hit by massive earthquakes, the damage of the lifts and escalators to be designed according to the Seismic Design Guideline was suppressed to certain level, and the effectiveness of the Seismic Design Guideline was confirmed.
\end{abstract}

\section{INTRODUCTION}

Approximately 20\% of the earthquakes having Magnitude 6 in the whole earth occur in Japan and surroundings, although the area is only $0.1 \%$ of the whole earth [1]. This is because Japan is located on the west side of the circum-Pacific seismic zone, and on 4 plates. People in Japan have experienced various earthquakes and have improved the seismic engineering based on damage from actual earthquakes.

The first electric passenger lift in Japan was installed in a building in Tokyo in 1890 [2], although the building was destroyed by a large earthquake in 1923. After that, lifts in Japan have experienced various large earthquakes, then the Seismic Design Guideline in Japan was published and revised according to the damage from earthquakes. In this decade, several large earthquakes attacked Japan. One is the Great East Japan Earthquake in 2011 that is the largest earthquake ever observed in Japan. The earthquake had large energy, long duration time and many aftershocks. The other is the Kumamoto Earthquake in 2016 that occurred in Kyushu Region. In the series of the Kumamoto Earthquakes, two large earthquakes having Japan Meteorological Agency (JMA) seismic intensity 7 that is the highest level of the scale occurred. The North Osaka Earthquake in 2018 was also the large earthquake that attacked a large city in Japan.

This paper provides changes of the Seismic Design Guideline in Japan and analyses of the damage of lifts and escalators from the Great East Japan Earthquake in 2011, the Kumamoto Earthquake in 2016 and the North Osaka Earthquake in 2018. 


\section{CHANGES OF SEISMIC DESIGN GUIDELINE IN JAPAN}

The aims of seismic design guideline in Japan are as follows. Lifts should continue to provide safe operation without any problem even after middle scale earthquakes that rarely occur, and should support the cage even if the other equipment gets damaged when very rare large scale earthquakes occur. Escalators must not detach and fall from one beam or both beams of a building even by large scale earthquakes that extremely rarely occur. The idea of these aims came from the Japanese seismic standard for buildings. In order to achieve the above-mentioned aims, the seismic design guideline for lifts and escalators in Japan has been revised based on the actual damages by various earthquakes.

Table 1 shows a history of major earthquakes and seismic standards or guidelines, and Fig. 1 shows epicenters of major earthquakes in Japan.

Before 1971, the official seismic design guidelines didn't exist in Japan, so companies designed the lifts and escalators by using their own seismic design criteria.

In 1972, the Disaster Prevention Standard was established by the Japan Elevator Association. This establishment is based on the damage of lifts by San Fernando Earthquake in 1971. In the earthquake, a counterweight fell and collided with a car. Thus, the standard considered derailment of cars and counterweights, prevention of overturning of traction machines and control systems, and seismic emergency operation. The design acceleration was uniform regardless of the region and the type of lifts.

In 1981, a Seismic Design Guideline was established by the Building Center of Japan based on the damage of lifts from Miyagi Earthquake in 1978. In the earthquake, derailment of counterweights, and movement of traction machines occurred. In addition, Enforcement Ordinance of Construction Standard Law in Japan was revised in 1981, so the Seismic Design Guideline reflected it. The Seismic Design Guideline considered improvement of countermeasures against derailment of cars and counterweights, improvement of prevention of overturning of traction machines and control systems, improvement of countermeasures against entanglements of ropes. The design acceleration in this edition considered differences according to the region and the type of lifts involved.

In 1998, a Seismic Design Guideline was issued by the Building Center of Japan based on the damage of lifts and escalators from Great Hanshin-Awaji Earthquake, so-called Kobe Earthquake in 1995. In the earthquake, counterweights fell, and equipment in the machine rooms moved and overturned. In addition, damage of escalators was also reported. Therefore, countermeasures against falling of counterweight blocks, and the increase of design earthquake level were added to the new Seismic Design Guideline. A classification of lifts by the use of a building was newly introduced. In addition, seismic design of escalators was newly described in the guideline.

In 2009, the Seismic Design Guideline was revised based on the damage of lifts from the Mid Niigata Prefecture Earthquake in 2004 and the Northwestern Chiba Earthquake in 2005. In the Mid Niigata Prefecture Earthquake, long period seismic waves that have predominant period of more than a few seconds were generated in Tokyo, so high-rise buildings and wire ropes of lifts resonated. In the Northwestern Chiba Earthquake, many lifts were stopped for a long time by the earthquake emergency operation, and passengers were trapped in lifts, although this earthquake was smaller than the other more destructive earthquakes. Thus, the revised guidelines considered countermeasures against resonance of long ropes and improvement of the earthquake emergency operation. The design acceleration considering amplification ratios of buildings and equipment was introduced. In addition, revision of an assessment method of guide rails, reinforcement of fall prevention measures for counterweight blocks and other measures were carried out.

In 2014 and 2016, the Seismic Design Guideline was revised based on the damage of lifts and escalator from the Great East Japan Earthquake in 2011 [3]. Lifts and escalators damaged by the earthquake as describe hereinafter, because the earthquake was the largest earthquake ever 
experienced in Japan. In addition, 4 escalators in shopping malls fell from the floors of buildings. Thus, the revised guidelines considered countermeasures of falling of escalators, and assessment of major support parts of lifts.

Table 1 History of major earthquakes and seismic standards or guidelines in Japan

\begin{tabular}{|c|c|c|}
\hline Year & Earthquake & $\begin{array}{c}\text { Publication and Revision of } \\
\text { Standard / Guideline }\end{array}$ \\
\hline \hline $\mathbf{1 9 7 1}$ & San Fernando Earthquake & Disaster Prevention Standard \\
\hline $\mathbf{1 9 7 2}$ & & \\
\hline $\mathbf{1 9 7 8}$ & Miyagiken-oki Earthquake & Seismic Design Guideline (1981) \\
\hline $\mathbf{1 9 8 1}$ & & Seismic Design Guideline (1998) \\
\hline $\mathbf{1 9 9 5}$ & Great Hanshin-Awaji Earthquake & \\
\hline $\mathbf{1 9 9 8}$ & & Seismic Design Guideline (2009) \\
\hline $\mathbf{2 0 0 4}$ & Mid Niigata Prefecture Earthquake & \\
\hline $\mathbf{2 0 0 5}$ & Northwestern Chiba Earthquake & Seismic Design Guideline (2014) \\
\hline $\mathbf{2 0 0 9}$ & & Seismic Design Guideline (2016) \\
\hline $\mathbf{2 0 1 1}$ & Great East Japan Earthquake & \\
\hline $\mathbf{2 0 1 4}$ & &
\end{tabular}

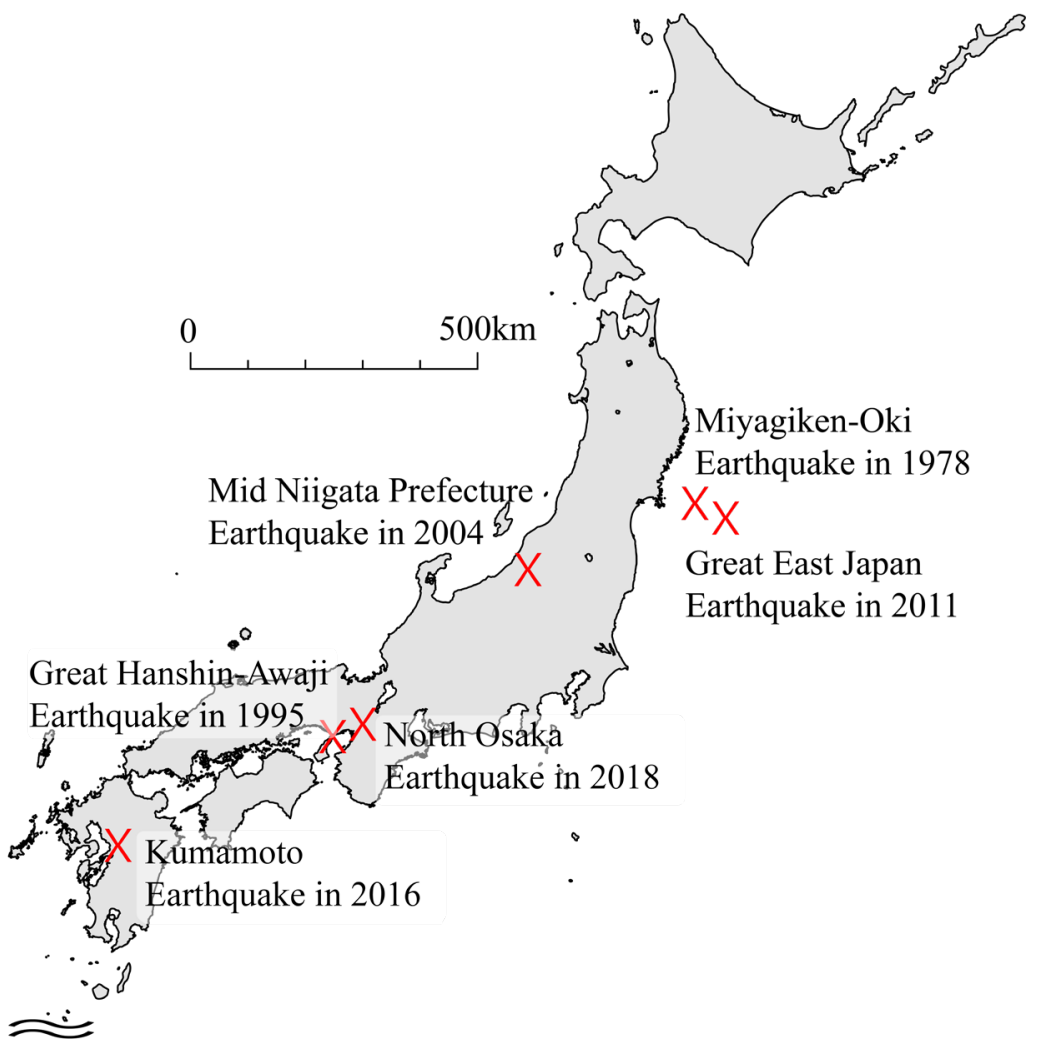

Figure 1 Epicenters of major earthquakes in Japan 


\section{COMPARISON OF SEISMIC DESIGN GUIDELINE}

There are some regulations regarding seismic design of lifts, such as EN81-77 that is applied in Europe and ASME A17.1 that is published by the American Society of Mechanical Engineers.

The ideas of seismic design methods and equipment that should be protected from earthquakes are similar to each other. For example, the regulations mainly apply methods using static seismic force based on the design acceleration, and express effective countermeasures for important equipment such as counterweights guide rails. However, some differences can be found. For example, the Japanese guideline and EN81-77 employ uniform design acceleration regardless of equipment, but ASME A17.1 employs design acceleration depending on the type of equipment. In addition, EN8177 considers the type of the ground, and the required countermeasures depends on the design acceleration. On the other hand, the Japanese guideline doesn't consider the type of the ground, although it considers the region where the building is located in, and same countermeasures are generally applied regardless of the design acceleration. In the Japanese guideline, lifts in low-rise buildings generally consider more than $4 \mathrm{~m} / \mathrm{s}^{2}$ of horizontal design acceleration. This design acceleration will be higher than other regulations.

One of the unique countermeasures in the Japanese guideline is a vibration detection system for long ropes in high rise buildings. The seismic wave that induces resonance of long ropes has long period and the level is small, so it is difficult to detect this kind of seismic waves. For example, the vibration detection system can estimate the displacement of long ropes by measuring vibration of the building and its duration. Snagging of ropes can be avoided by applying this system, and trapping people in lifts can consequently be avoided.

\section{DAMAGE FROM GREAT EAST JAPAN EARTHQUAKE IN 2011}

\subsection{Summary of earthquake}

The Great East Japan Earthquake was a series of disasters that originated in the off Pacific coast Tohoku Earthquake on March 11, 2011 at 14:46 JST. The hypocenter of the earthquake was at approximately $130 \mathrm{~km}$ east-southeast of the Oshika Peninsula, at a depth of $24 \mathrm{~km} \mathrm{[4].} \mathrm{The} \mathrm{moment}$ magnitude of the earthquake was 9.0 that was the largest earthquake among seismic records in Japan. Strong ground motion and tsunamis were generated by the earthquake, so that about 16,000 people died, about 2500 people went missing, more than 120,000 buildings completely collapsed, and more than 280,000 buildings partially collapsed [5].

The earthquake demonstrated many features as compared with conventional destructive earthquakes. For example, duration of the main shock was very long, that was about 6 minutes, and the seismic wave was transmitted to the whole area of Japan. Another feature was very large tsunamis. The maximum wave height was more than $9.3 \mathrm{~m}$, but actual height was not clear because the observation point was damaged by the tsunamis. The maximum water level height that was supposed from trace or watermark was more than $20 \mathrm{~m}$, and the maximum run-up height was more than $40 \mathrm{~m}$. About $90 \%$ of victims died from drowning by tsunamis, and much equipment in industrial facilities was covered with sea water. Additionally, lots of aftershocks occurred, the number of aftershocks of magnitude more than 5 was 779 as of April 30, 2012 [4].

Fig. 2 shows the characteristics of the ground motion observed in Sendai city, 170km away from the epicenter. Sendai is the main city in Tohoku district, and its population is more than 1,000,000. The plural strong ground motions attacked Sendai city over long time as shown in Fig. 1. 


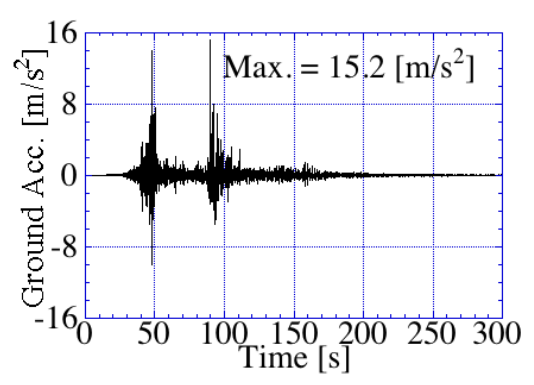

(a) Ground acceleration

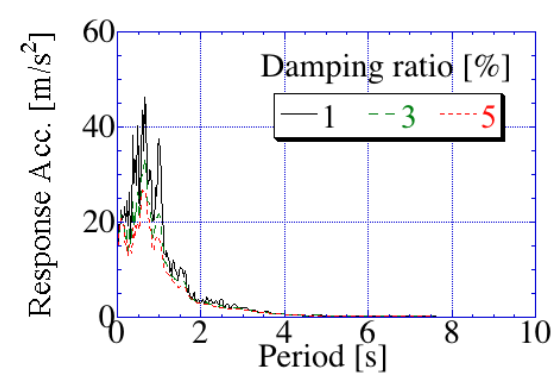

(b) Response acceleration spectra

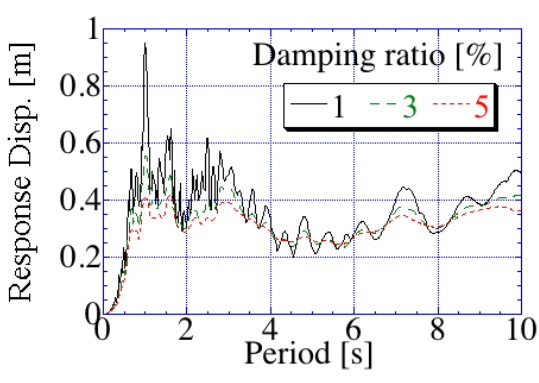

(c) Response

displacement spectra

Figure 2 Ground motion observed in Sendai city (K-NET Sendai NS wave)

\subsection{Investigation method}

An investigation regarding damage to lifts and escalators from the earthquake was carried out by the Japan Elevator Association [6]. The investigation was started from July when aftershocks decreased, because restoration of lifts and escalators was a priority just after the earthquake. Target earthquakes for the investigation were the main shock and aftershocks more than JMA seismic intensity $5+$ that occurred until June. Targets machines were lifts and escalators which the members of the Japan Elevator Association inspected, with exception of small freight lifts. The existence and cause of the damage, an edition of the Seismic Design Guideline that was applied when a lift was installed were investigated by a questionnaire. Contents of the questionnaire was determined based on damage by the Kobe Earthquake in 1995.

\subsection{Damage of lifts}

As the result of the investigation by using the questionnaire, damage was found in 8,921 out of 367,912 cases, so the incidence ratio was $2.43 \%$

Fig. 3 shows the incidence ratio by the JMA seismic intensity scale. The JMA seismic intensity is defined by Japan Meteorological Agency and is calculated from ground acceleration in consideration of frequency components. The minimum level is 0 , and the maximum level is 7 . As shown in Fig. 3 , more than $1 / 4$ of lifts in area of the JMA seismic intensity 7 were damaged. In addition, the incidence ratio increased when the JMA seismic intensity was more than $6+$.

Fig. 4 shows damage of lifts by the cause. As shown in Fig. 4, entanglements of ropes accounted for $1 / 4$ of total damage. The reason was that large areas in Japan including Tokyo where many buildings exist were affected by the earthquake. Vibration of ropes relates to such parameters as the height of a building, the length of a rope, and the ground condition. For example, Tokyo is located on a sedimentary layer, and long period seismic waves are excited by this layer. In general, high-rise buildings and long wire ropes have long natural period, so that there are risks of resonance. Then many damages by flooding also occurred. This is a one of the features of the Great East Japan Earthquake. Other mechanical structures were also damaged by large tsunamis [7]. In addition, a lot of damage that was caused by interaction with buildings such as entanglements of ropes, deformation of rails, and damage of hoistway equipment occurred. Close cooperation with structural engineers of buildings is strongly recommended to reduce the damage of lifts. Falling of counterweight blocks occurred as well as past destructive earthquakes. Although the number of the falling of counterweight blocks was few, it may result in human casualties. However no falling of counterweight blocks in lifts that were designed by applying the Seismic Design Guideline issued in 2009 occurred. Therefore, the guideline was revised effectively. 
Fig. 5 shows relationship between edition of the Seismic Design Guideline and the incidence ratio. Since the incidence ratio has decreased with the edition, the revision seems to have been effective.

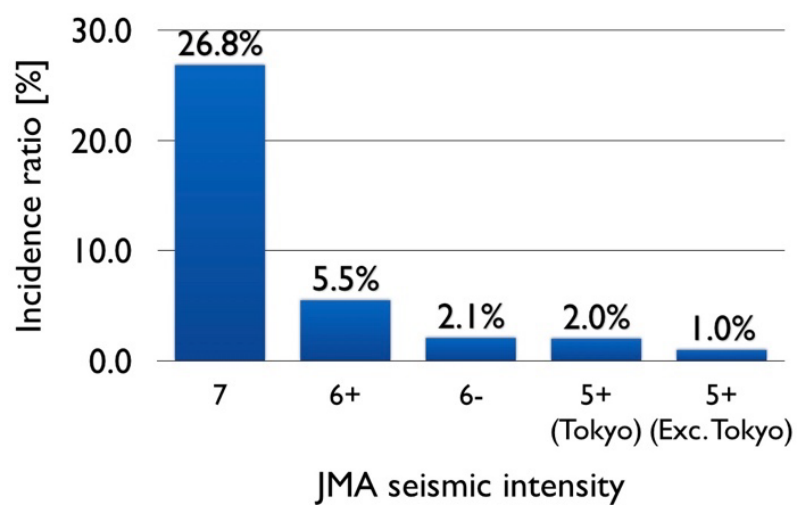

Figure 3 Incidence ratio of lift by Japan Meteorological Agency seismic intensity scale (Great East Japan Earthquake in 2011)

Entanglements of rope $23.8 \%$

Flooding $12.7 \%$

Derailment $12.6 \%$

Deformation of rail etc. $10.3 \%$

Damage of car Equip. $10.0 \%$

Damage of hall Equip. $7.2 \%$

Damage of hoistway Equip. $4.8 \%$

Damage by building failure $4.7 \%$

Damage of Equip. in machine room

Coming off of rope $1.8 \%$

Damage of hydraulic Equip. $1.5 \%$

Falling of counterweight $0.5 \%$

Etc. $6.0 \%$

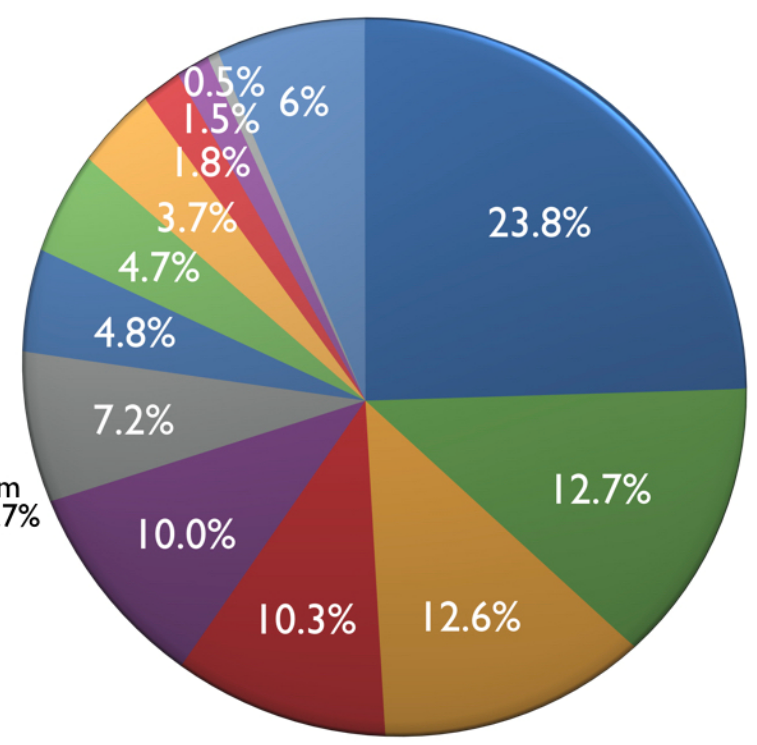

Figure 4 Damage of lift by cause (Great East Japan Earthquake in 2011)

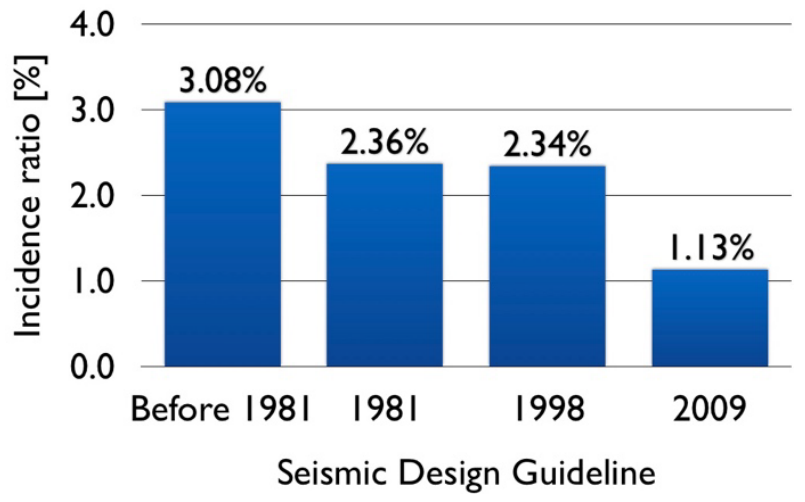

Figure 5 Relationship between edition of Seismic Design Guideline and incidence ratio of lift (Great East Japan Earthquake in 2011) 


\subsection{Damage of escalators}

Damage of escalators was found in 1,598 out of 40,967 cases, so the incidence ratio was $3.90 \%$.

Figure 6 shows damage of escalators by the cause. As shown in Fig. 6, damage by flooding that is one of the features of the Great East Japan Earthquake accounted for 1/5 of total damage. Apart from that, damage such as position shifts and damage of landing plates occurred. This damage might be caused by interaction between buildings and escalators.

In addition, 4 escalators in shopping malls fell from floors of buildings. Although the number of the falling of escalator was few, it may cause human casualties if passengers are on the escalators. Therefore, a project and revision of the guideline regarding fall accidents were carried out after the earthquake [8].

Figure 7 shows relationship between the edition of the Seismic Design Guideline and the incidence ratio. The incidence ratio of escalators designed before 1998 was smaller than escalators that were designed by applying the Seismic Design Standard issued in 1998. On the other hand, the ratio of escalators after 2009 decreased.

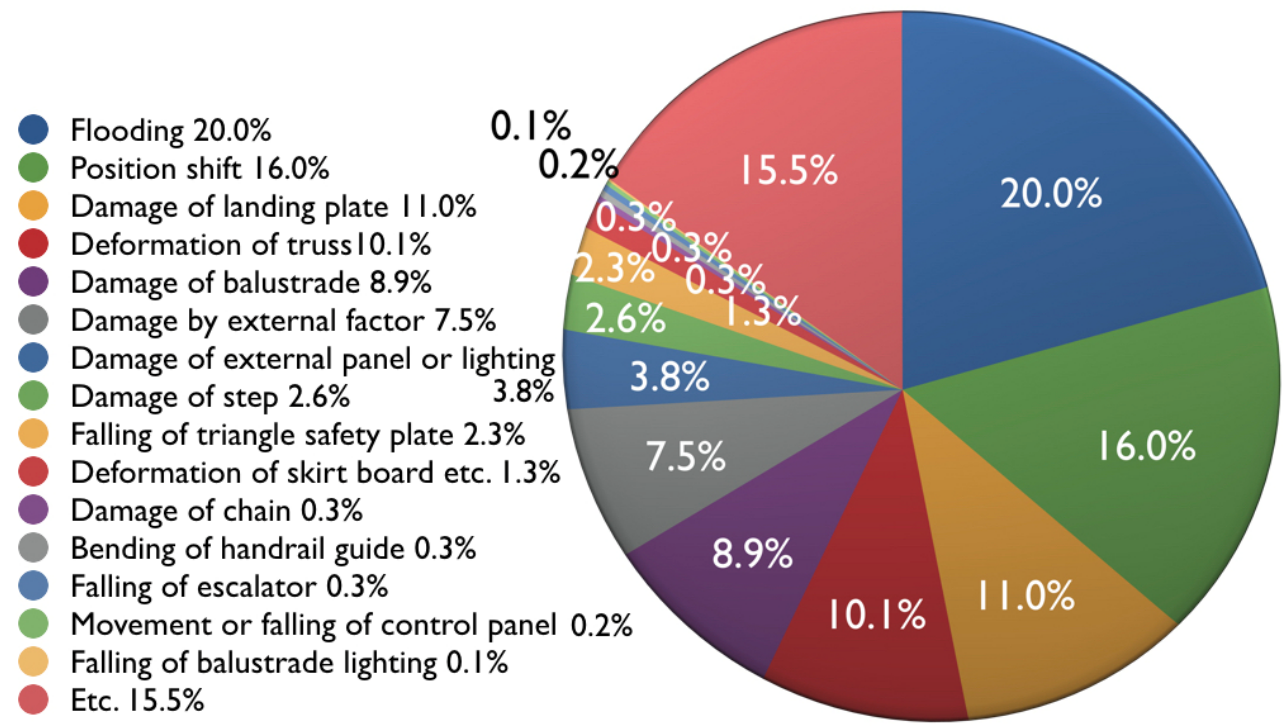

Figure 6 Damage of escalator by cause (Great East Japan Earthquake in 2011)

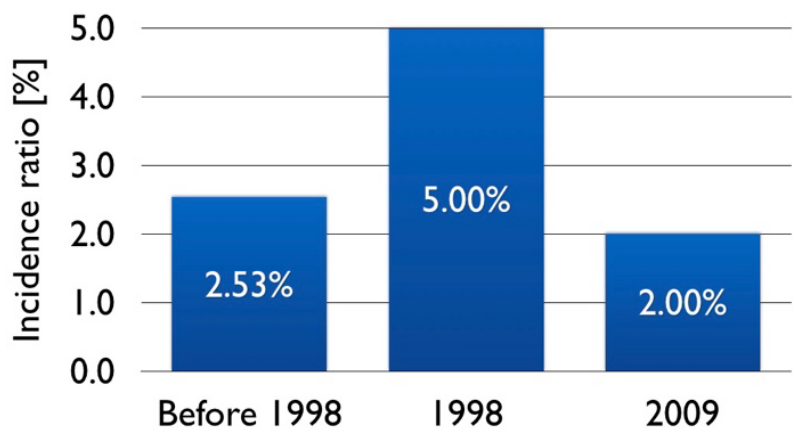

Seismic Design Guideline 


\section{Figure 7 Relationship between edition of Seismic Design Guideline and incidence ratio of escalator (Great East Japan Earthquake in 2011)}

\section{DAMAGE FROM KUMAMOTO EARTHQUAKE IN 2016}

\subsection{Summary of earthquake}

On April 14, 2016 at 21:26 JST, a strong near-field earthquake having moment magnitude 6.2 occurred in Kyushu Region that is southwest part of Japan. The hypocenter of the earthquake was Kumamoto Prefecture, at a depth of $11 \mathrm{~km}$. The JMA seismic intensity was 7 that is the largest level of the intensity, but this was a foreshock. About 28 hours later, on April 16 at 1:25 JST, another nearfield strong earthquake having moment magnitude 7.0 occurred in same area, at a depth of $12 \mathrm{~km}$. This was the main shock. Deaths from the series of earthquakes was 228 people. More than 9,000 buildings completely collapsed, and more than 45,000 buildings were partially damaged [9]. The feature of the earthquake was strong ground motion and landslides. Industrial facilities in Kumamoto Prefecture were damaged by the earthquake, and the main cause of damage of mechanical structures was strong vibration [10].

Fig. 8 shows the characteristics of the ground motion of the main shock that was observed in Mashiki town, $7 \mathrm{~km}$ away from the epicenter. Strong ground motion was observed as shown in Fig. 8. In addition, the duration time was long despite the near-field earthquake, and the response displacement spectra was large compared with other earthquakes.

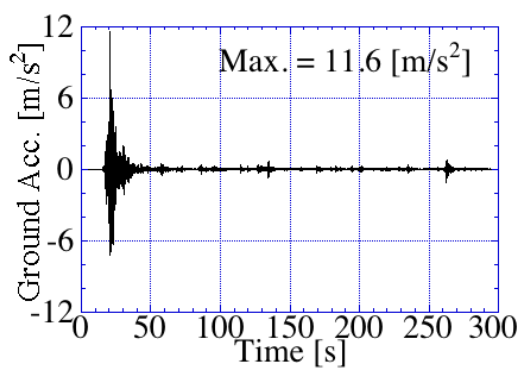

(a) Ground acceleration

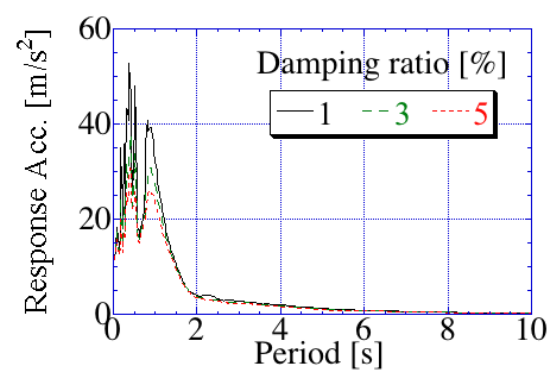

(b) Response acceleration spectra

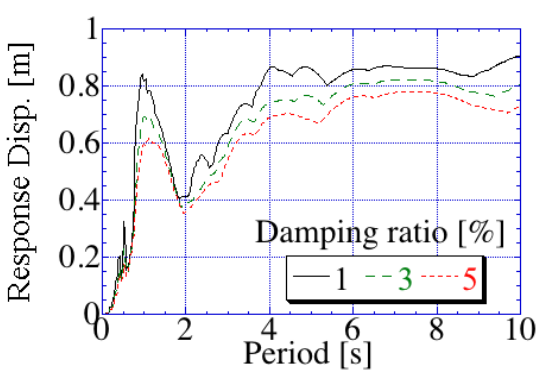

(c) Response displacement spectra

Figure 8 Ground motion observed in Mashiki town (KiK-NET Mashiki EW wave)

\subsection{Investigation method}

Same investigation method as the Great East Japan Earthquake was also carried out, namely an investigation using the questionnaire was conducted by the Japan Elevator Association from June to July in 2016 [11]. Target earthquakes for the investigation were the foreshock, the main shock and 3 aftershocks more than JMA seismic intensity 5+ that occurred in April. The investigation area is 13 prefectures with the maximum JMA seismic intensity was more than 4 .

\subsection{Damage of lifts}

As the result of the investigation by using the questionnaire, damage was found in 1,027 out of 95,424 cases, so the incidence ratio was 1.08\%. This result was smaller than the Great East Japan Earthquake.

Fig. 9 shows damage of the lifts by the cause. As shown in Fig. 9, damage related to buildings such as entanglements of ropes, damage of rails, cars, halls equipment mainly occurred. The duration time was long and response displacement spectra was high as shows in Fig. 8, so the ground motion caused 
the entanglements of ropes. Five cases of falling of counterweight blocks occurred, but these happened at lifts that were designed by applying the Seismic Design Guideline issued in 1981 or before.

Fig. 10 shows relationship between the edition of the Seismic Design Guideline and the incidence ratio. Since the incidence ratio decreased with the edition as well as the Great East Japan Earthquake, the revision seems to have been effective.

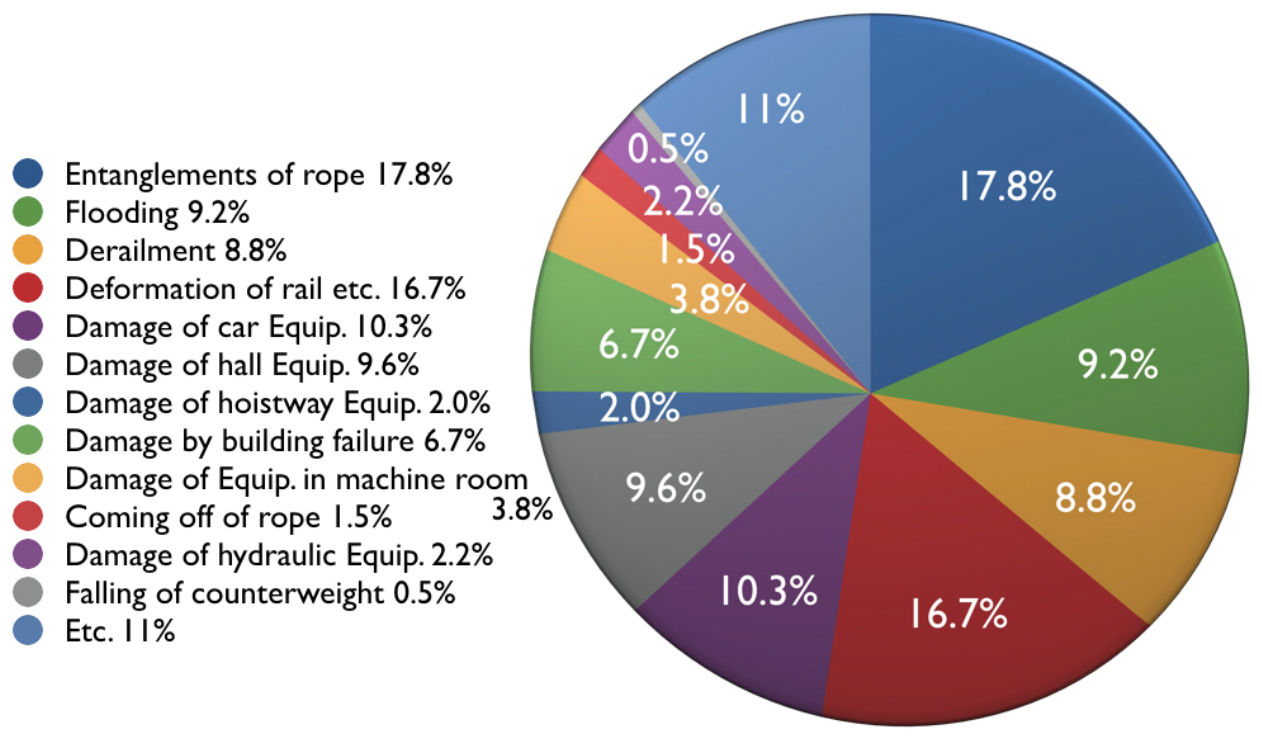

Figure 9 Damage of lift by cause (Kumamoto Earthquake in 2016)

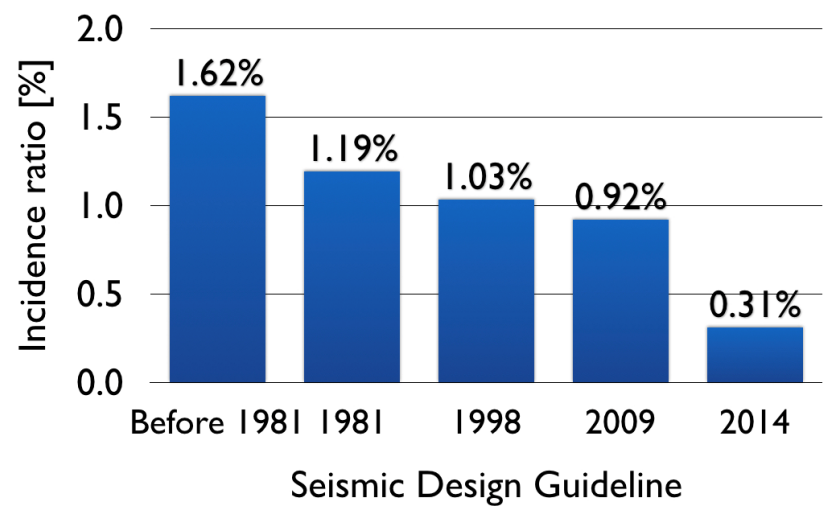

Figure 10 Relationship between edition of Seismic Design Guideline and incidence ratio of lift (Kumamoto Earthquake in 2016)

\subsection{Damage of escalator}

Damage of escalators was found in 330 out of 8,744 cases, so the incidence ratio was $3.77 \%$.

Fig. 11 shows damage of the escalators by the cause. As shown in Fig. 11, damage mainly occurred in landing plates, external panels or lighting, and this damage was related to interaction with buildings. In addition, no fall accident of escalator occurred. 
Fig. 12 shows relationship between the edition of the Seismic Design Guideline and the incidence ratio. Although the incidence ratio of escalators after 2014 was small, the ratio increased with the edition. In order to clarify the reason of this result, an investigation in consideration of buildings is needed.

Flooding $5.8 \%$

Position shift $3.6 \%$

Damage of landing plate $17.6 \%$

Deformation of truss $2.4 \%$

Damage of balustrade $4.5 \%$

Damage by external factor $0.3 \%$

Damage of step $0.9 \%$

Falling of triangle safety plate $8.2 \%$

Deformation of skirt board etc. $3.9 \%$

Bending of handrail guide $2.4 \%$

Falling of balustrade lighting $1.5 \%$

Etc. $32.1 \%$
Damage of external panel or lighting

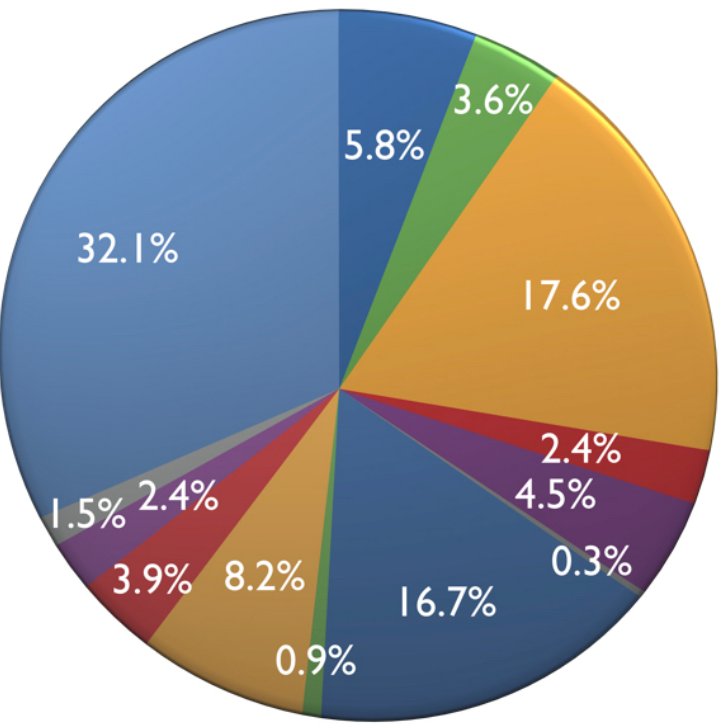

Figure 11 Damage of escalator by cause (Kumamoto Earthquake in 2016)

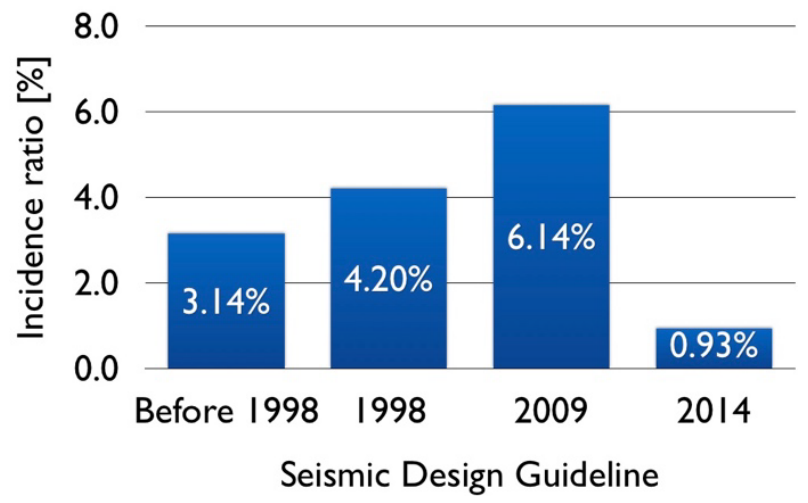

Figure 12 Relationship between edition of Seismic Design Guideline and incidence ratio of escalator (Kumamoto Earthquake in 2016)

\section{DAMAGE FROM NORTH OSAKA EARTHQUAKE IN 2018}

\subsection{Summary of earthquake}

On June 18, 2018 at 7:58 JST, a strong near-field earthquake having moment magnitude 5.5 occurred in the north Osaka. The hypocenter of the earthquake was northern part of Osaka Prefecture, at a depth of $13 \mathrm{~km}$. The maximum JMA seismic intensity was 6-. Death from the earthquake was 6 people. More than 20 buildings completely collapsed, and more than 61,000 buildings were partially damaged [12]. Osaka is one of the major cities of Japan with large number of population and there are many buildings with lifts, so various damage by the earthquake was observed. 
Fig. 13 shows the characteristics of the ground motion observed in Takatsuki city, $3 \mathrm{~km}$ away from the epicenter. As shown in Fig. 13, the maximum acceleration, duration time and spectra were smaller than the Great East Japan Earthquake and the Kumamoto Earthquake.

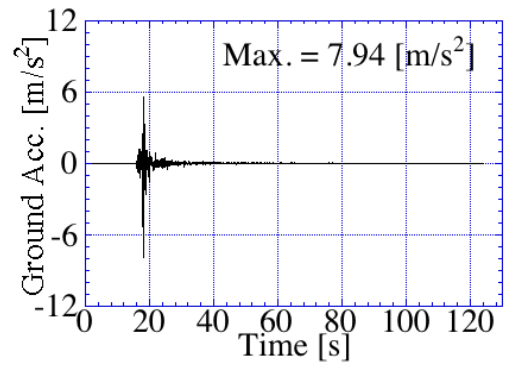

(a) Ground acceleration

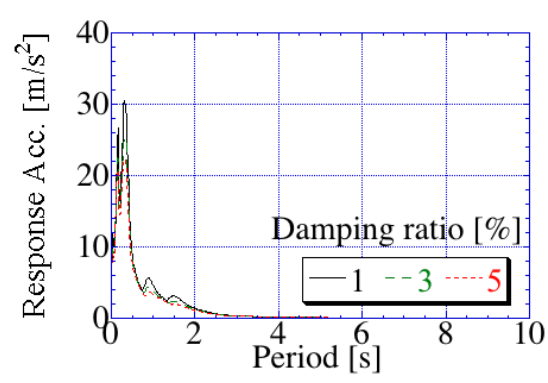

(b) Response acceleration spectra

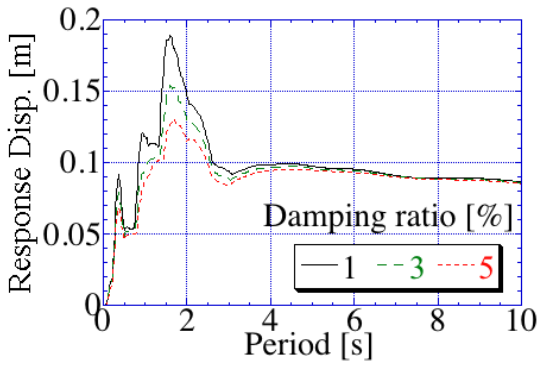

(c) Response displacement spectra

Figure 13 Ground motion observed in Takatsuki city (K-NET Takatsuki EW wave)

\subsection{Investigation method}

Same investigation method as the Great East Japan Earthquake and the Kumamoto Earthquake was also applied, namely an investigation using the questionnaire was conducted by the Japan Elevator Association from July to September in 2018 [13]. Target earthquake for the investigation was the main shock, and the investigation area is 10 prefectures with the maximum JMA seismic intensity is more than 4 .

\subsection{Damage of lifts}

As a result of the investigation by using the questionnaire, damage was found in 729 out of 216,835 cases, so the incidence ratio was $0.34 \%$. This incidence ratio was smaller than the Great East Japan Earthquake and the Kumamoto earthquake, because the scale of the earthquake was smaller as shown in Fig. 13. However, operations of about 63,000 lifts were stopped by the earthquake and passengers were trapped in 346 lifts [14], and the number of the operation stops and the trapping is larger than the Great East Japan Earthquake and the Kumamoto earthquake. The operation stop was mainly caused by the emergency operation based on the Seismic Design Guideline, and almost all lifts were returned to service within the next 2 days. The trapping was mainly caused by the high acceleration or momentary opening of doors, and almost all passengers trapped in lifts were rescued within 3 hours.

Fig. 14 shows the incidence ratio by the JMA seismic intensity scale. As shown in Fig. 14, no damage of lifts occurred if the JMA seismic intensity was 4 , and the incidence ratio became large if the JMA seismic intensity was 6-.

Fig. 15 shows damage of lift by cause. As shown in Fig. 15, ratio of derailments and damage of car equipment are large compared with other earthquakes. This damage was mainly occurred in lifts designed with the Seismic Design Guidelines issued in 1998 or before. On the other hand, damage by flooding was small because the earthquake was the near-field earthquake and tsunami didn't occur. Entanglements were also smaller than other earthquakes, because the scale of the earthquake was small as shown in Fig. 13. In other words, the maximum response displacement spectrum with damping ratio of $1 \%$ was less than $0.2 \mathrm{~m}$, predominant period is small, and the duration time is so short that ropes didn't resonate. 


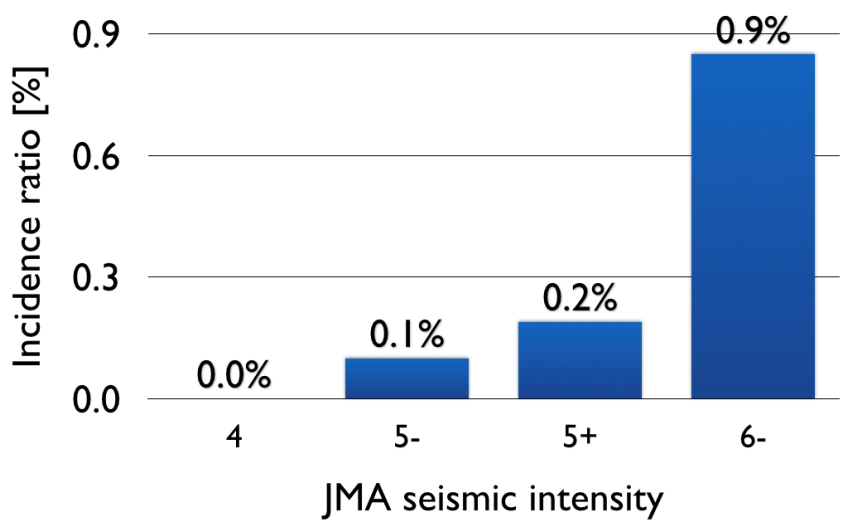

Figure 14 Relationship between JMA seismic intensity and incidence ratio of lift (North Osaka Earthquake in 2018)

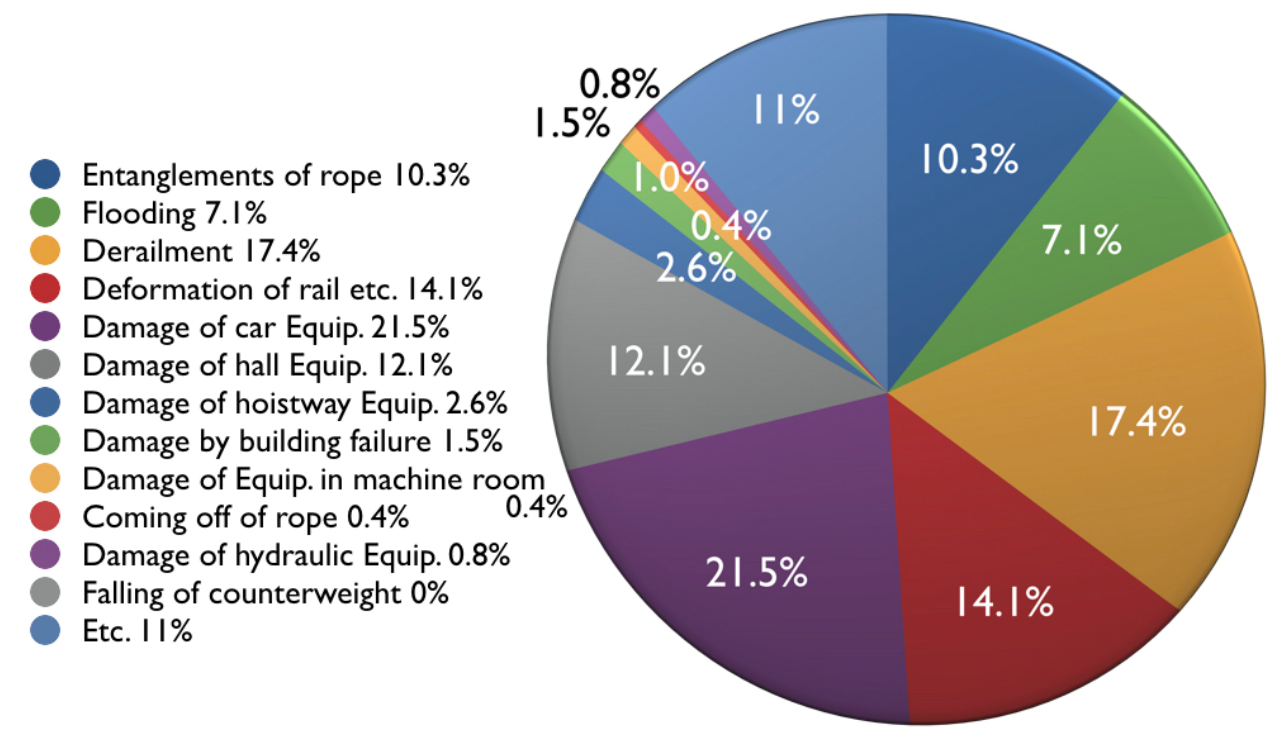

Figure 15 Damage of lift by cause (North Osaka Earthquake in 2018)

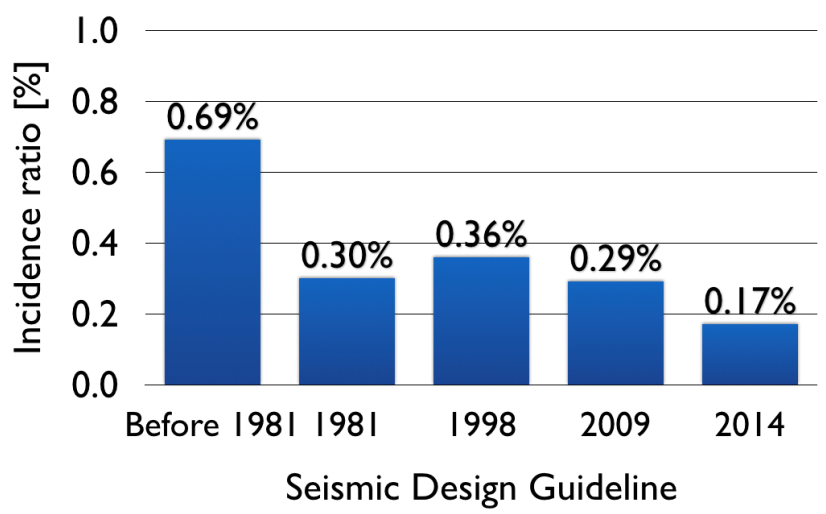

Figure 16 Relationship between edition of Seismic Design Guideline and incidence ratio of lift (North Osaka Earthquake in 2018) 
Fig. 16 shows relationship between edition of the Seismic Design Guideline and the incidence ratio. Since the incidence ratio decreased with the edition as well as the Great East Japan Earthquake and the Kumamoto Earthquake, the revision seems to have been effective.

\subsection{Damage of escalator}

Damage of escalators was found in 159 out of 21,204 cases, so the incidence ratio was $0.75 \%$. This incidence ratio was smaller than the Great East Japan Earthquake and the Kumamoto earthquake as well as lifts.

Fig. 17 shows the incidence ratio by the JMA seismic intensity scale. As shown in Fig. 17, no damage of escalator occurred if the JMA seismic intensity was 4, and the incidence ratio became large if the JMA seismic intensity was 6-. This tendency was same as the damage of lifts.

Fig. 18 shows damage of escalators by cause. As shown in Fig. 18, damage of landing plates was remarkable. The landing plates are one of the boundaries between building structures. Thus, the response and interaction with building structures should be considered to reduce the damage of the landing plates. In addition, Etc. accounted for $44.7 \%$ of total damage, so the detailed investigations and revisions of the contents of the questionnaire should be considered.

Fig. 19 shows relationship between the edition of the Seismic Design Guideline and the incidence ratio. The incidence ratio somehow increased with the edition as well as the damage by the Kumamoto Earthquake. As stated above, damage of escalators mostly occurred in boundaries with building structures. Therefore, this tendency should be evaluated from the viewpoint of both escalators and buildings.

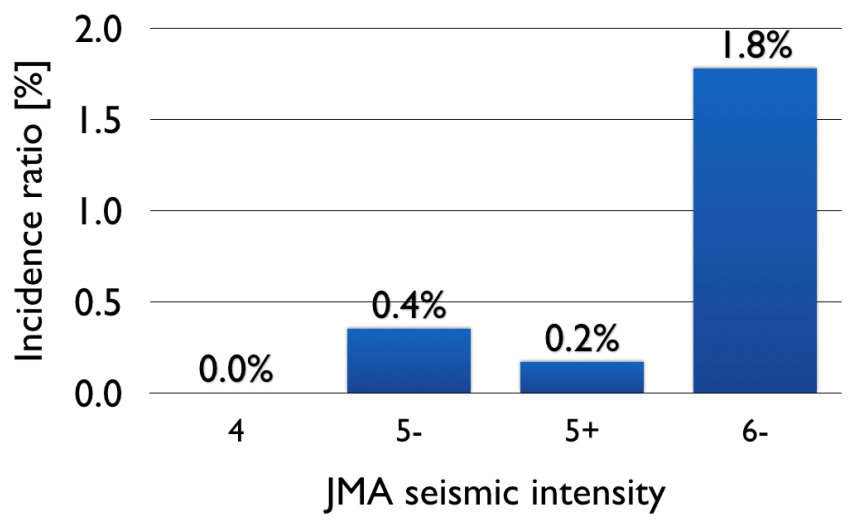

Figure 17 Relationship between JMA seismic intensity and incidence ratio of escalator (North Osaka Earthquake in 2018) 
Flooding $9.4 \%$

Position shift $8.2 \%$

Damage of landing plate $27.0 \%$

Deformation of truss $1.3 \%$

Damage of balustrade $3.1 \%$

Damage by external factor $0.3 \%$

Damage of external panel or lighting

Damage of step $0 \%$

Falling of triangle safety plate $0 \%$

Deformation of skirt board etc. $4.4 \%$

Bending of handrail guide $0.6 \%$

Falling of balustrade lighting $0 \%$

Etc. $44.7 \%$

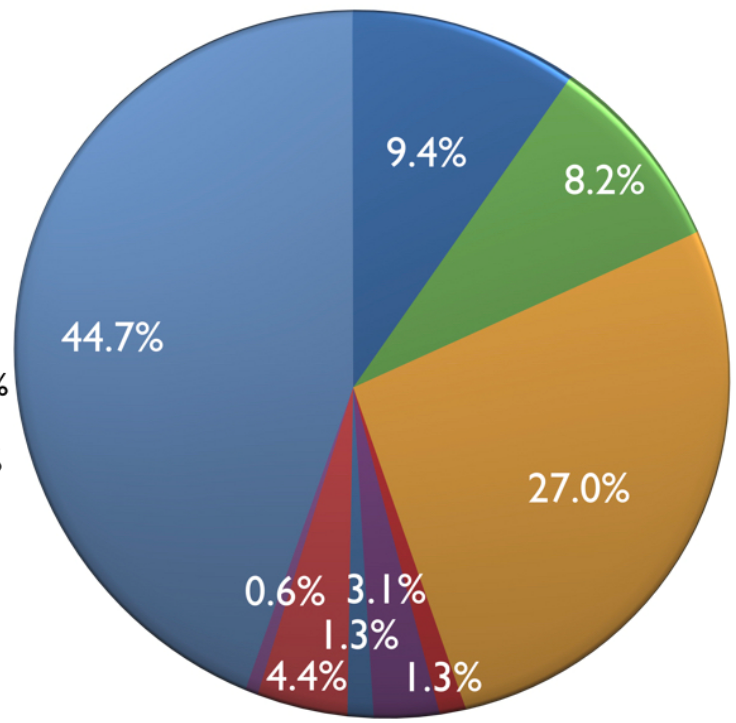

Figure 18 Damage of escalator by cause (North Osaka Earthquake in 2018)

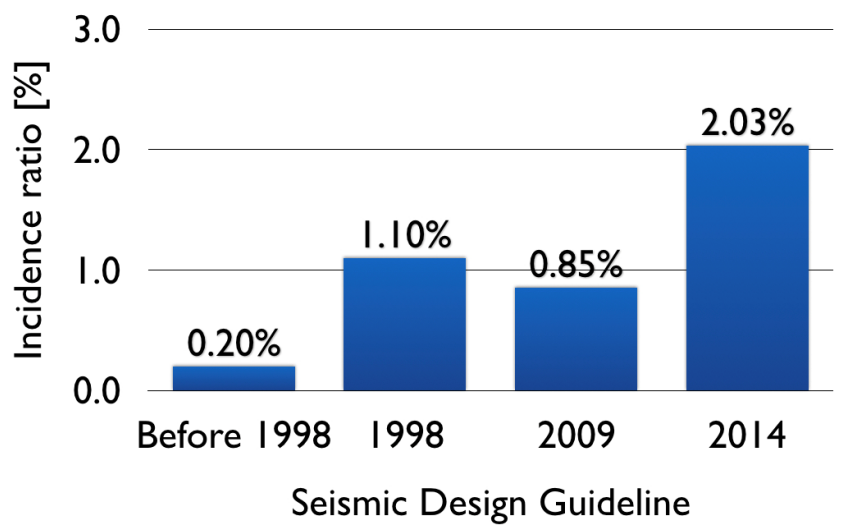

Figure 19 Relationship between edition of Seismic Design Guideline and incidence ratio of escalator (North Osaka Earthquake in 2018)

\section{CONCLUSION}

In this paper, changes of the Seismic Design Guideline in Japan were introduced, then investigation results regarding damage of lifts and escalators from large earthquakes were reported. The results are summarized as follows;

- Seismic Design Guidelines of Japan were revised according to actual damage from large earthquakes. From the investigation results of three large earthquakes, that is the Great East Japan Earthquake, the Kumamoto Earthquake and the North Osaka Earthquake, the revisions of the standard for lifts were almost effective to improve seismic reliability of lifts.

- The effectiveness of revisions of the Seismic Design Guidelines for escalators was not clearly confirmed. In order to analyse the effectiveness in detail, additional investigations of the damage considering interaction between building structures are required.

- The damage mode changes according to frequency components and scale of the ground motion. 
- The damage of lifts and escalators remarkably occurs when the JMA seismic intensity is more than about 6. The Seismic Design Guidelines provide that lifts must operate after earthquakes that rarely occur, and lifts must maintain functions to suspend cars even if the equipment is damaged after earthquakes that very rarely occur. For example, the probability that an earthquake having the JMA seismic intensity of $6+$ or more occurs in Tokyo within the next 30 years is $7.8 \%$ [15]. Therefore, the Seismic Design Guidelines satisfy this requirement.

- Lifts and escalators are generally installed in buildings, and damage in boundaries between lifts or escalators and building structures were remarkable. Therefore, close cooperation with structural engineers of buildings is strongly recommended to reduce the damage of lifts and escalators.

- There are other seismic regulations for lifts such as EN81-11 and ASME17.1. These regulations apply similar technique to the Japanese guidelines, although the design acceleration is different from each other. Therefore, it is expected that other regulations will be also effective for seismic events.

\section{REFERENCES}

[1] Cabinet Office, Government of Japan, White Paper on Disaster Management 2010. http://www.bousai.go.jp/kaigirep/hakusho/h22/bousai2010/html/zu/zu001.htm, (2010), (Accessed 28 November 2019), (in Japanese).

[2] N. Mitsui, Historical Development of Rope Type Elevator Technology. Survey Reports on the Systemization of Technologies, No. 9, 65, (2009).

[3] The Japan Building Equipment and Elevator Center Foundation and The Japan Elevator Association, Elevator/Escalator Engineering Standards. (2018), (in Japanese).

[4] Japan Meteorological Agency, Information on the 2011 Great East Japan Earthquake. http://www.jma.go.jp/jma/en/2011_Earthquake/Information_on_2011_Earthquake.html, (Accessed 28 November 2019).

[5] National Police Agency of Japan, Situation of damage and police activities for Great East Japan Earthquake in 2011. https://www.npa.go.jp/news/other/earthquake2011/pdf/higaijokyo.pdf, (2018), (Accessed 28 November 2019), (in Japanese).

[6] S. Fujita, M. Shimoaki, T. Miyata, Report on Seismic Damages of Elevators and Escalators by the Great East Japan and Recovery Situations and Lessons for Future Mitigation. Proceedings of Dynamics and Design conference 2012, 653.pdf, (2012), (in Japanese).

[7] Japan society of mechanical engineers, Lessons Learned from the Great East Japan Earthquake Disaster. https://www.jsme.or.jp/jsme/uploads/2016/08/Great-East-Japan-EarthquakeDisaster-Full-Text.pdf, 14-23, (2014), (Accessed 28 November 2019).

[8] S. Fujita, M. Shimoaki, Investigations on Safety Measures for Lifts and Escalators; Outcomes from 9 the Researches Funded by the Building Standard Development Promotion Program, Japanese Ministry of Land, Infrastructure and Transport (MLIT). Proceedings of 9th symposium on lift \& escalator, 9-1-9-14, (2018).

[9] Cabinet Office, Government of Japan, Damage situation on earthquake with epicenter of Kumamoto district, Kumamoto prefecture in 2016 (as of April 13, 2017). http://www.bousai.go.jp/updates/h280414jishin/pdf/h280414jishin_39.pdf, (2017), (Accessed 28 November 2019), (in Japanese). 
[10] I. Nakamura, O. Furuya, K. Minagawa, S. Fujita, Seismic Damage and Influence to Industrial Facilities in the 2016 Kumamoto Earthquake. Proceedings of Dynamics and Design conference 2017, 225.pdf, (2017), (in Japanese).

[11] Japan Elevator Association, Report of Damage investigation of elevator and escalator by earthquake with epicenter of Kumamoto district, Kumamoto prefecture. http://www.nelekyo.or.jp/about/elevatorjournal/pdf/Journal13 10.pdf, (2017), (Accessed 28 November 2019), (in Japanese).

[12] Fire and Disaster Management Agency of Japan, Damage of the earthquake with epicenter of the northern part of Osaka prefecture and response status of fire agency etc. (Part 32, as of November 2, 2018). https://www.fdma.go.jp/disaster/info/items/190820oosakafuhokubujisinn32.pdf, (2018), (Accessed 28 November 2019), (in Japanese).

[13] Japan Elevator Association, Report of Damage investigation of elevator and escalator by earthquake with epicenter of the northern part of Osaka prefecture. http://www.nelekyo.or.jp/about/elevatorjournal/pdf/Journal24_11.pdf, (2019), (Accessed 28 November 2019), (in Japanese).

[14] Ministry of Land, Infrastructure, Transport and Tourism of Japan, Analysis of damage status of elevator by earthquake with epicenter of the northern part of Osaka prefecture and action status of the countermeasure. http://www.mlit.go.jp/common/001293499.pdf, (2019), (Accessed 28 November 2019), (in Japanese).

[15] National Research Institute for Earth Science and Disaster Resilience, J-SHIS Japan Seismic Hazard Information. http://www.j-shis.bosai.go.jp/en/, (Accessed 28 November 2019), 